Supporting Information for Publication

\title{
Uncovering the Structure and Stability of
}

\section{Thermoelectric $\mathrm{La}_{3-\mathrm{x}} \mathrm{Te}_{4}-\mathrm{Ni}$ Composites using High-}

\section{Resolution and In Situ TEM}

Melonie P. Thomas, ${ }^{a}$ Ahamed Ullah, ${ }^{a}$ Dean Cheikh, ${ }^{b}$ Ayanthi Thisera, ${ }^{a}$ Manisha De Alwis Goonatilleke, ${ }^{a}$ Sabah Bux, ${ }^{* b}$ and Beth S. Guiton*a

${ }^{a}$ Department of Chemistry, University of Kentucky, 505 Rose Street, Lexington, Kentucky 40506, USA

b Thermal Energy Conversion Materials Research Group, Jet Propulsion Laboratory/California Institute of Technology, 4800 Oak Grove Drive, Pasadena, CA 91109, USA 


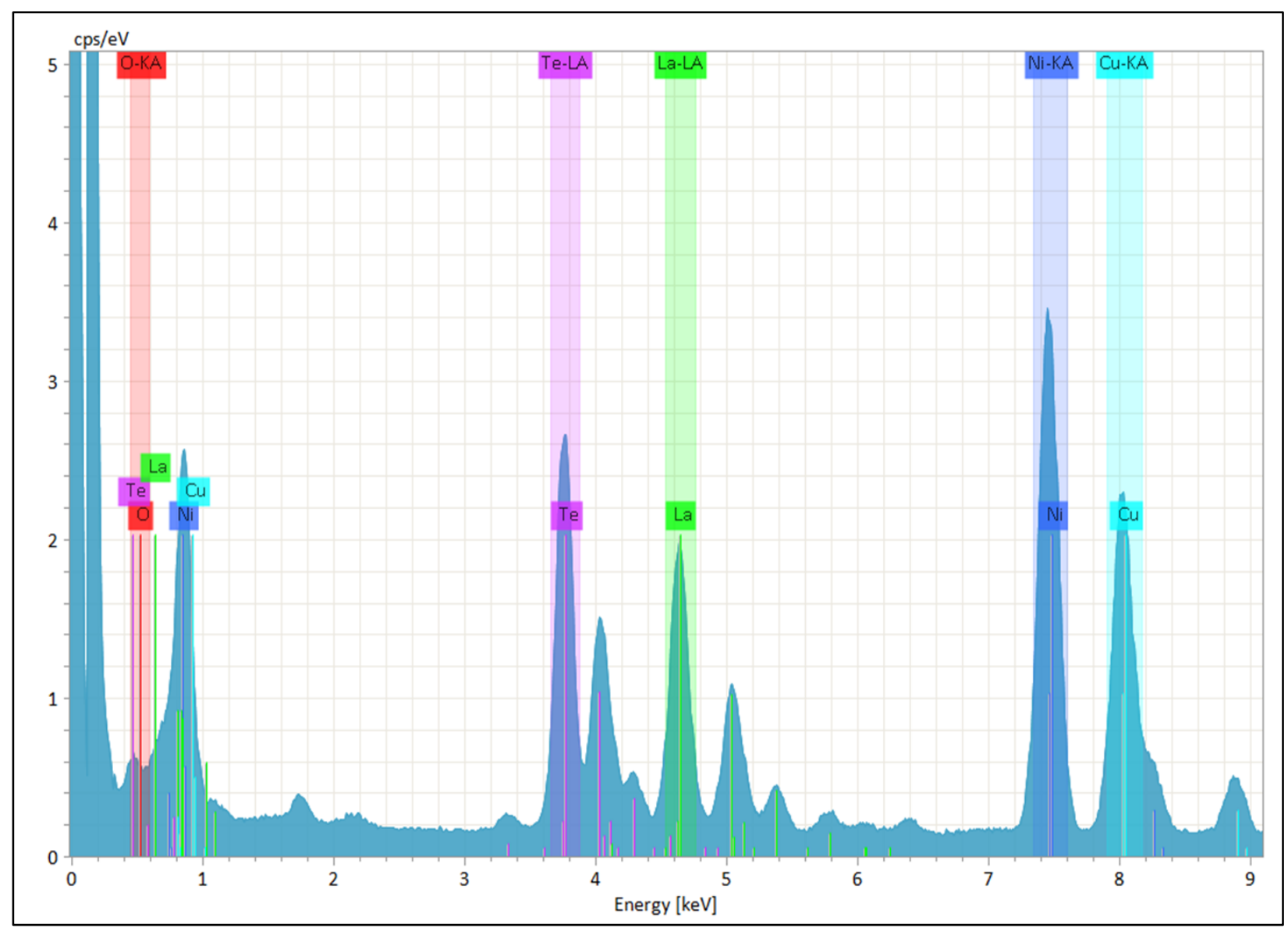

Figure S1. EDS spectrum of Figure 1 (d-g) showing the presence of $\mathrm{La}, \mathrm{Te}$, and $\mathrm{Ni}$ in the $\mathrm{La}_{3-\mathrm{x}} \mathrm{Te}_{4^{-}}$ $\mathrm{Ni}$ sample. The absence of an $\mathrm{O}$ peak indicates successful sample preparation and transfer processes. 

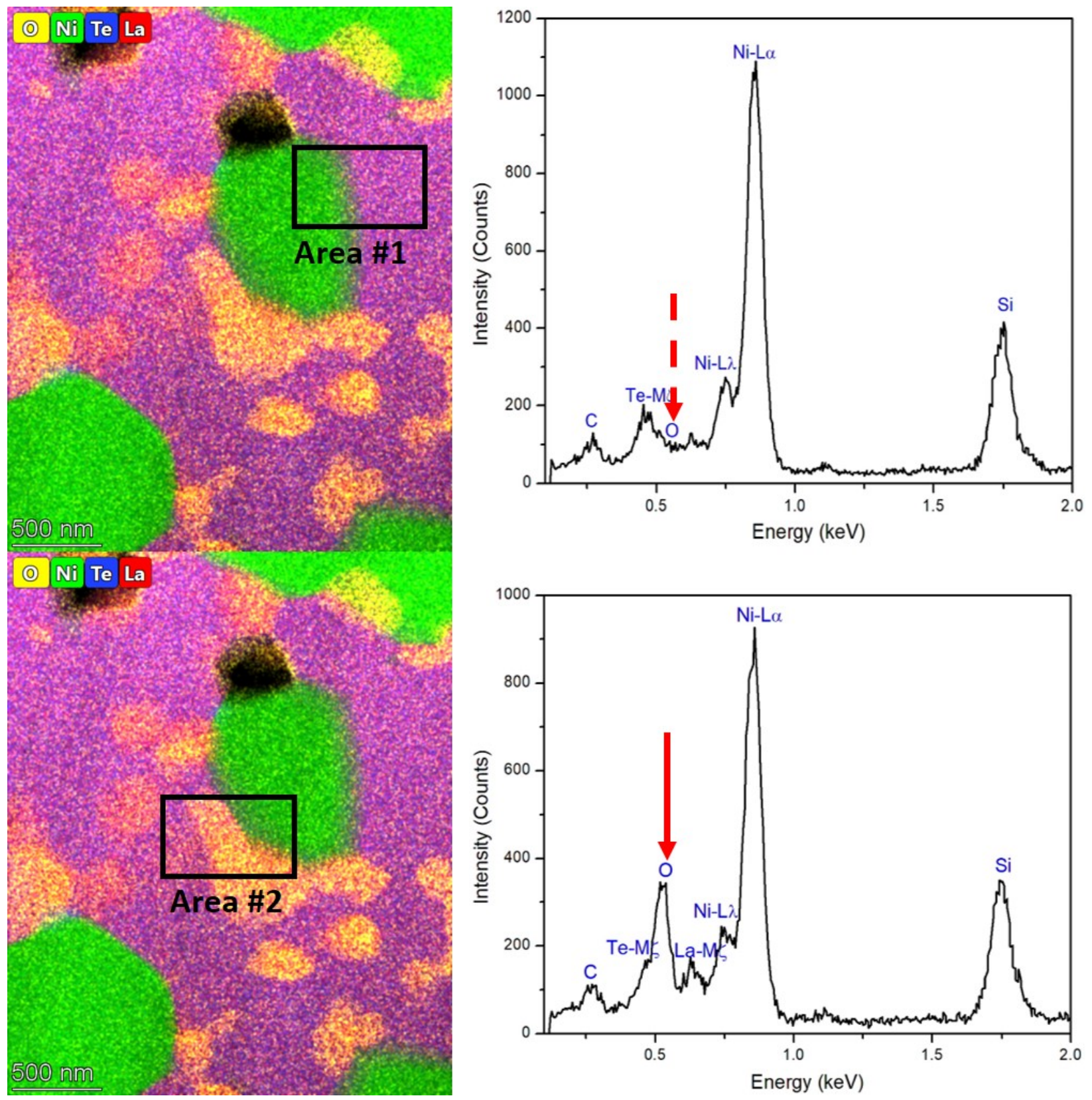

Figure S2. Two EDS spectra representing two areas from the ROI of the partially oxidized sample in Figure 6(a). Area 1 and 2 represents non-oxidized and oxidized interfaces, respectively (red dashed and solid arrows indicate absence and presence of the O signal in EDS spectra). 